\title{
Las investigaciones del Marqués de Cerralbo en el «Cerro Villar» de Monreal de Ariza: Arcobriga ${ }^{1}$
}

\author{
CARMEN JimÉnEz SANZ*
}

\begin{abstract}
RESUMEN ABSTRACT
Se presenta un avance de los trabajos que se están realizando sobre la aportación del XVII Marqués de Cerralbo a la disciplina arqueológica, orientados al conocimiento de la Historia de la Arqueología española en las primeras décadas del siglo Xx. Se revisa el caso del yacimiento romano de Arcobriga desde las circunstancias que motivaron

su descubrimiento, objetivos de las investigaciones, metodología, desarrollo de los trabajos de campo y gabinete,

We introduce an advance of our work about XVII Marquis of Cerralbo and his contribution to the spanish Archaeology History, in the first decades of this century.

Following a brief history about his life, you will find a review of the case of Arcobriga's roman site: circumstances that involved its discovery, research objectives, methodology, development of works, contributions of any other specialists and so on.
\end{abstract} intervención de otros especialistas, etc., partiendo de una breve introducción a la figura del Marqués de Cerralbo.

\section{PALABRAS CLAVE \\ Arcobriga; Marqués de Cerralbo; historiografia; arqueología; metodología.}

* Colaboradora del Museo Cerralbo (Madrid).

- El artículo recoge y actualiza el texto de la comunicación presentada en el IV Coloquio Galego de Museos "Investigación e Museos", celebrado en el Museo de Pontevedra en Diciembre de 1994 y que, por error de edición, no figuró en las Actas. 
Dentro del amplio panorama de la investigación en Museos, cobra importancia la recuperación de datos referentes a antiguas intervenciones arqueológicas, que sólo pueden valorarse correctamente cuando se conoce el contexto temporal en que fueron realizadas.

Además de la revisión y análisis de materiales arqueológicos procedentes de esas primeras exploraciones, que permiten la reinterpretación de los yacimientos originarios, se hace necesario el estudio de los condicionantes técnicos, científicos, sociales, económicos y políticos que influyeron en el desarrollo de tales actividades. La valoración historiográfica de los mismos, se orienta al conocimiento de la Historia de la Arqueología española de principios de siglo?

Siguiendo esta idea nos ha parecido interesante presentar un avance de los trabajos, emprendidos recientemente desde el Museo Cerralbo, sobre la contribución del Marqués de Cerralbo a la disciplina arqueológica. El caso concreto son las excavaciones que se efectuaron en la ciudad de Arcobriga, ubicada en el "Cerro Villar» de Monreal de Ariza (Zaragoza), cuyo trazado urbano y materiales datan de época romana (siglos I a.C. - III d.C.).

Varias razones justifican la elección: Se trata de un yacimiento de tipología única en la trayectoria de Cerralbo, cuya revisión parcial se inició en la década anterior ${ }^{3}$. Una extensión representativa de la ciudad fue excavada hasta los años 20 y parte de sus resultados llegaron a publicarse; las numerosas referencias bibliográficas posteriores se basan en aquéllos, ya que todavía no ha visto la luz un proyecto de recuperación integral que desarrolle nuevas campañas de excavación, documentación y valore el futuro del conjunto arqueológico. Desafortunadamente Arcobriga sigue siendo un yacimiento apenas conocido por la sociedad y aparentemente abandonado por las administraciones central y autonómica ${ }^{4}$.

\footnotetext{
2 Labor iniciada por numerosos investigadores, incluída como asignatura en los nuevos planes de estudio, contemplada en cada vez más temarios de oposición de técnicos de museos y de Patrimonio incluída como sección en congresos arqueológicos, objeto de Tesis Doctorales, etc. Y promovida por instituciones como el C.S.I.C., que organizó durante 1988 un primer Congreso publicado por AACE, J. y Olmos, R. (coord.) Historiografía de la Arqueología y de la Historia Antigua en España (siglos xvilixx). Madrid, 1991. El segundo se realizó en 1995: MorA, G. y Díaz-AnDREu, M. (eds.) La cristalización del pasado: Génesis y desarrollo del marco institucional de la Arqueología en España, Málaga, 1997.

3 Las principales publicaciones son: Lostal PRos, J. Arqueología del Aragón romano, Zaragoza, 1980, catálogo en el que presenta nuevas descripciones y planimetrías de las termas y el templo (prospección 1973-74). BeltaÁn Lloris, M. (dir) Arcóbriga (Monreal de Ariza, Zaragoza). Zaragoza, 1987, edición anotada del tomo $V$ de las Páginas de la Historia Patria, referencia fundamental para las investigaciones sobre la ciudad.

4 La idea, no contrastada, de que Cerralbo agotó el yacimiento; la ubicación de Arcobriga en terreno rústico, dañada por las labores agrícolas y expoliada frecuentemente; su aparente olvido
} 
La fuente de información original para acometer su estudio son las obras El Alto Jalón, que recoge el discurso presentado en la Real Academia de la Historia el 26 de Diciembre de 1909 y el tomo quinto de la obra Páginas de la Historia Patria por mis excavaciones arqueológicas, ganadora del Premio Internacional Martorell que se disputó en Barcelona en 1911. El carácter de ambas, una concebida como discurso tras dos campañas de excavación y la otra como avance de un estudio más completo, presentado apresuradamente al Premio citado tras cuatro campañas, han condicionado tanto la presentación y análisis de los primeros estudios, como nuestra aproximación actual. También es necesario mencionar un trabajo poco conocido, editado por la Bilioteca Patria, titulado Del hogar castellano, estudios históricos y arqueológicos, que reproduce integramente el texto dedicado a la ciudad en la publicación de 1909 , sin ilustraciones ${ }^{5}$.

Lejos de aportar nuevos datos sobre análisis tipológicos de materiales - la interpretación histórica del yacimiento, este artículo se orienta a la búsqueda de referencias bibliográficas y documentales que puedan ofrecer información acerca de las circunstancias que motivaron el descubrimiento del enclave arqueológico, objetivos de las excavaciones, metodología, desarrollo de los trabajos de campo y gabinete, intervención de otros especialistas, etc., partiendo de una semblanza del Marqués de Cerralbo y una introducción sobre cómo se iniciaron sus estudios arqueológicos.

\section{EL MARQUÉS DE CERRALBO}

Arcobriga constituye la primera excavación extensa del XVII Marqués de Cerralbo, Enrique de Aguilera y Gamboa (1845-1922), fundador del Museo del mismo nombre sito en Madrid, cuya figura empieza a ser valorada lejos de los prejuicios que, décadas atrás, provocaron el olvido de su obra arqueológica 6 .

en comparación al interés demostrado hacia otras ciudades romanas de Aragón como Celsa (Velilla de Ebro), Bilbilis (Calatayud) o Caesaraugusta (Zaragoza), que demandan continuas campañas de excavación, son factores que han podido influir en la escasa atención recibida por el yacimiento.

5 Aguilera Y Gamboa, E. de, Marqués de Cerralbo "Arcóbriga" en El Alto Jalón. Descubrimientos arqueológicos. Madrid, 1909, págs. 106-132. Agullera y GamBOA, E. de Páginas de la Historia Patria por mis excavaciones arqueológicas. Tomo V: Arcóbriga. Madrid, 1911 (obra inédita). Agullera y GamBOA, E. de "Arcóbriga". Del hogar castellano, estudios históricos y arqueológicos. Biblioteca Patria, Tomo CIII, Madrid, s/d, págs. 91-124.

${ }^{6}$ Las semblanzas sobre este mecenas se deben, especialmente, a Juan Cabré, arqueólogo, amigo y primer director del Museo Cerralbo, por disposición testamentaria: CABRE AGUILÓ, J. “EI Marqués de Cerralbo (necrología)". Actas y Memorias de la Sociedad Española de Antropología, 
Además de político (fue militante y jefe del Partido Tradicionalista), literato y amante de las Bellas Artes, dedica a la Arqueologia las útimas décadas de su vida. Su vinculación surge de un temprano interés por la Numismática, el coleccionismo de obras de arte y la investigación histórica, además de una formación humanística que se ve complementada con la realización de numerosos viajes por Europa.

Su primer contacto con la llamada Arqueología de campo se dará en 1895, al financiar una campaña de excavación en el yacimiento madrileño de Ciempozuelos. A partir de 1907 y, tras el ingreso en la Real Academia de la Historia en 1908, su intervención como asesor, promotor y director en la documentación y excavación de más de un centenar de yacimientos, tales como Torralba, Ambrona, Alpanseque, Luzaga o Aguilar de Anguita le proporcionó el reconocimiento como arqueólogo desde distintas instancias. Dispuso que sus hallazgos fueran donados a los museos nacionales (actuales Museo Nacional de Ciencias Naturales y Museo Arqueológico Nacional), participó en la redacción de la Ley de Excavaciones de 1911 y en los órganos de control creados por ésta (entre otros, Junta Superior de Excavaciones y Antigüedades y Comisión de Investigaciones Paleontológicas y Prehistóricas), impulsó los estudios de Arte Rupestre y fue miembro, además, de la Real Academia Española y de la de Bellas Artes de San Fernando.

Por otro lado, la repercusión que tuvieron las publicaciones y comunicaciones presentadas, especialmente al XIV Congreso Internacional de Antropología y Arqueología Prehistóricas de Ginebra (1912), facilitó la vinculación a instituciones de carácter científico y cultural nacionales y extranjeras como la Sociedad Española para el Progreso de las Ciencias, Instituto Imperial de Berlin y de Paleontología Humana de Paris, Academia Pontificia Romana dei Nuovi Lincei, Sociedad de Anticuarios de Londres, etc.

Etnografia y Prehistoria. Tomo I, Cuadernos $2^{\circ}$ y $3^{\circ}$, Madrid, 1922, págs. 171-183. CABRE, J. «EI Marqués de Cerralbo". Boletín de la Sociedad Española de Excursiones. Tomo XXX, Madrid, 1922, págs. 1-7. Cabré, J. “El Marqués de Cerralbo". Coleccionismo, 117, Madrid, 1922, págs. 3-7. CABRÉ, J. "El Marqués de Cerralbo. I. Sus donaciones científicas. Su biografía». Ibérica. El progreso de las Ciencias y de sus aplicaciones, 451, 1922, págs. 285-287. CABRÉ, J. "El Marqués de Cerralbo. II. Sus descubrimientos arqueológicos". Ibérica. El progreso de las Ciencias y de sus aplicaciones, 453, 1922, págs. 314-317. JiMÉNEZ SANZ, C. “Pioneros: Enrique de Aguilera y Gamboa, Marqués de Cerralbo". Revista de Arqueologia, 182, 1996, págs. 52-57. Navascués, P., Conde, C. y Jiménez, C. El Marqués de Cerralbo. Madrid, 1996. MorÁn, J.A. y CABRE, E. «El Marqués de Cerralbo y Juan Cabré». Boletín de la Asociación Española de Amigos de la Arqueología, 36, 1996, págs. 23-35. NAVAscués, P. y JiménEZ, C. «EI XVII Marqués de Cerralbo y su aportación a la arqueología española" en MORA, G. y DiAz-ANDREU, M. (eds.) La cristalización del pasado: Génesis y desarrollo del marco institucional de la Arqueología en España, Málaga, 1997, págs. 507-513. BARRIL, M. y CeRdeño, M.L. “El Marqués de Cerralbo: un aficionado que se institucionaliza» en Mora, G. y DíAz-ANDREu, M. (eds.) La cristalización del pasado..., págs. 515-527. 


\section{INICIO DE LOS ESTUDIOS}

Las investigaciones en el área del Alto Jalón, que comprende parte de las provincias de Soria, Guadalajara y Zaragoza, se realizan desde su residencia de verano de Santa María de Huerta (Soria) durante las temporadas que Cerralbo pasaba dedicado, inicialmente, al estudio del monasterio cisterciense allí ubicado y a la figura del arzobispo Ximénez de Rada.

Estos últimos culminan el 31 de Mayo de 1908 con el discurso de ingreso en la Real Academia de la Historia, texto que aporta las primeras referencias de Cerralbo a la posible identificación de Arcobriga y el Cerro Villar y las del académico Juan Catalina, que en la contestación a dicho discurso describe brevemente las comprobaciones y descubrimientos que alli se estaban efectuando ${ }^{7}$. También será Catalina quien mencione la realización de exploraciones arqueológicas en el monasterio ${ }^{8}$ que, en caso de demostrarse, constituirían las primeras excavaciones dirigidas por Cerralbo, años antes de su vinculación oficial a los trabajos de campo en Ciempozuelos.

El eje y pretexto de los estudios en la cuenca alta del Jalón fue la reinterpretación de la vía romana $\mathrm{n} .^{\circ} 24$ Ab Emerita Caesaraugustam (Mérida-Zaragoza) y parte de la 25 del Itinerario de Antonino, en el tramo entre Segontia (Sigüenza) y Aquae Bilbilitanorum (Alhama de Aragón) y la ubicación de la mansio Arcobriga.

Desde el siglo XVI los historiadores localizaban Arcobriga en el actual Arcos de Jalón (Soria). Cerralbo discrepaba del trazado que implícaba dicha identificación, basándose en razones geográficas, históricas, valoración de restos epigráficos, prospecciones y excavaciones arqueológicas que le llevaron a proponer el yacimiento del Cerro Villar como mansio. Aunque la hipótesis no fue unánimemente aceptada al principio ${ }^{9}$, tal identificación se mantiene en la actualidad en los mismos términos que

7 Aguilera y Gamboa, E. de El Arzobispo D. Rodrigo Ximénez de Rada y el Monasterio de Santa María de Huerta, Madrid, 1908, págs. 95-101 y 366-367, respectivamente. Parte de esta obra, junto con el discurso de contestación de J. Catalina, un capítulo introductorio a la formación de la Sierra Ministra y la descripción de Arcóbriga, están reproducidos en AGUILERA y GAMBOA, E. de Del hogar castellano. Estudios históricos y arqueológicos. Biblioteca Patria, Tomo ClII, Madrid, s/d.

${ }^{8}$ Catalina García, J. Santa María de Huerta (Historia y descripción). Madrid, 1891, pás. 67,73-75.

- Taracena Aguirre, B. "Vías romanas del Alto Duero". Anuario del Cuerpo Facultativo de Archiveros, Bibliotecarios y Arqueólogos, Vol. II. Madrid, 1934, pág. 11. En esta obra de referencia fundamental se mantenía la identificación con Arcos. 
expuso su descubridor ${ }^{10}$; a ello contribuyó el descubrimiento en el yacimiento de una tésera de hospitalidad, cuyo texto incluía el nominativo Arcobrig(ensis) ${ }^{11}$.

Por otra parte, la identificación antigua se basaba en un hallazgo epigráfico, la lápida publicada por el cronista Ambrosio de Morales; su traducción fue reproducida por Cean Bermúdez en la voz "Arcos", añadiendo que existían restos de una antigua población, mansio de dos vías que unían Mérida y Zaragoza ${ }^{12}$. Hübner consideró dicha referencia como falsa o dudosa en el C.I.L., al no conservarse la lápida ni tener certeza del lugar de procedencia.

Para Cerralbo la metodología en el estudio de la red viaria romana partía del conocimiento intenso del terreno y estudio y recorrido personal de los trazados posibles, primera razón por la que no aceptaba la idea predominante. El camino que pasara por Arcos, siguiendo la margen izquierda del Jalón es angosto con desfiladeros peligrosos para uso militar, resultando más coherente el trazado desde Sigüenza al Campo Torance, por la Senda Galiana hasta la frontera con Aragón, ruta también frecuentada en épocas posteriores.

Recorrió detenidamente los alrededores de Arcos, llegando a excavar en el Monte de las Viñas, lugar tradicionalmente asociado a Arcobriga que no reunía las condiciones defensivas que las Fuentes determinaban en una mansio, en donde no localizó resto arqueológico alguno. Por último, inició las excavaciones en el Cerro Villar, paraje en el que tiempo atrás localizó en superficie abundantes fragmentos cerámicos y material de construcción ${ }^{13}$.

10 Unión Académica Internacional. Tabula Imperii Romani. Hoja K-30: Madrid. Caesaraugusta. Clunia. Madrid, 1993, pág. 51, obra que omite las referencias bibliográficas de Cerralbo. LOSTAL, J. "La reducción de la ciudad de Arcóbriga según el Itinerario de Antonino". Bimilenario de Zaragoza, Symposium de ciudades augústeas, Il. Zaragoza, 1976, págs. 139-143. LostaL, J. Arqueología del Aragón... págs. 200-207 describen e identifican la ciudad del Cerro Villar con Arcobriga, circunstancia corroborada por un detallado análisis de distancias entre mansiones.

Las primeras referencias de identificación en Arcos de Jalón y Monreal de Ariza son recopiladas por lostal, J. Arqueología del Aragón... págs. 200-201; BeltRÁn, M. Arcóbriga... pág. 11; y Magallon Botaya, M.A. La red viaria romana en Aragón. Colección Estudios y Monografias, 3. Zaragoza, 1987, pág. 188.

11 Según CABRÉ, J. « El Marqués de Cerralbo. II. Sus descubrimientos"... pág. 316 la tésera se localizó en Arcobriga durante 1920; posteriormente fue estudiada por M. Gómez Moreno, que facilitó la transcripción a TOVAA, A. «EI bronce de Luzaga y las téseras de hospitalidad latinas y celtibéricas". Emerita, XVI, 1948, págs. 83-84, comentada también por BELTRÁN, M. Arcóbriga... pág. 44.

12 Cean Bermudez, J.A. Sumario de las Antigüedades Romanas que hay en España, en especial las pertenecientes á las Bellas Artes. Madrid, 1832, págs. 135-136.

13 Aguilera y Gamboa, E. de El Arzobispo Don Rodrigo... págs. 366-367. Aguilera y Gamboa, E de “Arcóbriga”... págs. 106-109; AGUILERA y GaMBOA, E. de Arcóbriga?... págs. 5-9. 


\section{ARCOBRIGA}

La ciudad romana, situada en el valle del Jalón, ocupa las laderas y cumbres del Cerro Villar, entre la Cañada Hermosa y la de Poyatos; conserva una doble línea de muralla, restos de construcciones urbanas de tipo público (basílica, templo, aljibe, edificios de almacenamiento, termas...) y distintas viviendas con calles empedradas, todas ellas distribuidas en áreas amesetadas.

Parece ser que, al mismo tiempo, se excavaba en el enclave urbano y en la necrópolis celtibérica situada en el llano, considerada por Cerralbo como el cementerio de los primeros habitantes del yacimiento; razón por la que algunos de sus materiales se mezclaron con los de la ciudad ${ }^{14}$, bien durante el proceso de excavación u ordenación en los almacenes del palacio de Santa María de Huerta, bien tras su donación ${ }^{15}$.

Las intervenciones realizadas entre 1911-20 no llegaron a publicarse, siendo uno de los trabajos que Cerralbo, próximo a su fallecimiento, encomendó a Juan Cabré ${ }^{16}$. Así, existe mayor número de estructuras descubiertas que la observable en las fotografías originales, permaneciendo inéditos hasta los años 80 conjuntos como las termas o el aljibe situado entre la primera y segunda meseta, excavados posteriormente ${ }^{17}$.

Aunque el estudio y las visitas a la zona se habian iniciado con anterioridad, las campañas de excavación dieron comienzo en 1908 y se sucedieron anualmente hasta 1911 , con una duración total de doce años ${ }^{18}$. El Marqués

14 Beltrán, M. Arcobriga... Agullera y Gamboa, E. de Páginas de la Historia Patria por mis excavaciones arqueológicas. Tomo IV: Necrópolis ibéricas. Madrid, 1911 (obra inédita); AguILERA y GamboA, E. de "Nécropoles ibériques" Congrés International d'Anthropologie et d'Archéologie préhistoriques. Ginebra, 1912, págs. 593-627. AgullerA y GamboA, E. de "Las necrópolis ibéricas". Congreso de la Asociación Española para el Progreso de las Ciencias. Madrid, 1916.

15 La entrega de hallazgos al Museo Arqueológico Nacional, dispuesta en el testamento de Cerralbo, tuvo lugar en 1926 y 1940, recién finalizada la guerra civil, segun la documentación que obra en el Archivo del mencionado centro y reflejada en BARRIL, M. y CERDEÑo, M.L. «EJ Marqués de Cerralbo: un aficionado..." págs. 521-524, 526-527.

16 CABRÉ, J. “El Marqués de Cerralbo. I. Sus donaciones...” pág. 287. CABRÉ, J. «EJ Marqués de Cerralbo. Il. Sus descubrimientos..." pág. 317. En estas publicaciones el autor firma como "Director del Museo del Excmo. Sr. Marqués de Cerralbo y delegado para la publicación de las obras inéditas de Arqueología de dicho prócer". Tarea inabarcable, teniendo en cuenta su intensa trayectoria profesional como investigador y arqueólogo de campo que debió supeditar, temporalmente, a tareas como la elaboración del Inventario de obras de arte del Museo Cerralbo.

17 Lostal, J. Arqueología del Aragón... Beltrán, M. Arcóbriga... Beltrán, M. «Roma: República y Alto Imperio". Estado actual de la Arqueología en Aragón, tomo I, Zaragoza, 1990, págs. $215-262$.

18 Agullera y Gamboa, E. de "Arcóbriga"... pág. 112. Aguilera y Gamboa, E. de Arcóbriga?... pág. 9. CABRE, J. «EI Marqués de Cerralbo (necrología)" pág. 178. 
de Cerralbo, ante la negativa de venta de los propietarios, arrendó los te-

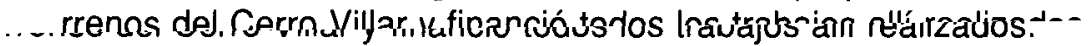

Bajo su dirección personal se fueron descubriendo el entramado urbano fortificado y los materiales arqueológicos, que se conservan actualmente en el Museo Arqueológico Nacional y han sido estudiados en distintos momentos ${ }^{19}$. El Museo de Zaragoza custodia los hallazgos posteriores, fruto de prospecciones realizadas por dicha institución y la Universidad de Zaragoza entre 1973-1978 ${ }^{20}$.

La metodología de excavación utilizada, como en la de la mayoría de yacimientos conocidos a principios de siglo, presenta múltiples carencias desde una óptica actual. Aquélla tenía su explicación en la idea decimonónica que perseguía el descubrimiento de muros y recuperación de materiales preciosos que ilustraran posteriores hipótesis históricas ${ }^{21}$, sin prestar apenas atención al método estratigráfico ${ }^{22}$, que ya se venía empleando en los estudios geológicos.

No parece que existiera un reticulado previo de la superficie, efectuándose zanjas prospectoras que, unas veces sondeaban el terreno y otras, continuaban trazados estructurales con la intención de descubrir plantas que permitieran identificar sus construcciones.

19 Pafís, P. “La Collection Cerralbo". Le Musée Archéologique National de Madrid. París, 1936, págs. 31-44. ARGENTE OLIVER, J.L. "Los yacimientos de la Colección Cerralbo a través de los materiales conservados en los fondos del M.A.N.". XIV Congreso Nacional de Arqueología (Vitoria, 1975). Zaragoza, 1977, págs. 587-598. MARINE ISIDRO, M. “Las fíbulas romanas del Cerro Villar (Monreal de Ariza, Zaragoza)" Trabajos de Prehistoria, 35, 1978, págs. 371-394. JIMÉNEZ SALVADOR, J.L. y LIz GUIRAL, J. "Inscripción romana sobre elemento arquitectónico de las termas de Arcobriga» Juan Cabré Aguiló (1882-1982) Encuentro de homenaje. Zaragoza, 1984, págs. 217-222. MEDRANO, M. "Algunas monedas procedentes de Monreal de Ariza" Caesaraugusta, 63, 1986, págs. 161 169. Guiral Pelegrin, C. y Mostalac Carfillo, A. "La pintura mural romana de Arcobriga (Monreal de Ariza, Zaragoza)" I Coloquio de pintura mural romana en España. (Valencia, 1989). Valencia, 1992, págs. 99-105. CABAllero Zoreda, L. (dir.) Arcóbriga Il. Las cerámicas romanas. Zaragoza, 1992. BarRIL VICENTE, M. "Colección Marqués de Cerralbo" en Marcos, A. (coord.). De gabinete a Museo. Tres siglos de Historia. Museo Arqueológico Nacional. Madrid, 1993, págs. 406-413.

20 Referencias facilitadas por D. Miguel Beltrán, director del mencionado Museo.

21 «...No conseguí objetos de valor, lo que es muy lógico, pues Arcóbriga?, pereció asaltada, muriendo sus habitantes al filo del hierro enemigo, e incendiadas sus viviendas (...) Barbaros, que la destruyeron, robándola antes".

"Pero si objetos de valor no tuve, fotografíanse muchos procedentes de las excavaciones, que proclaman las etapas, las costumbres, los usos y las aficiones de los Arcobricenses". Aguilera y Gamboa, E. de Arcóbriga?... pág. 52.

22 En otros yacimientos Cerralbo hace referencia a la estratigrafía, aportando en ocasiones dibujos, como el del Castro Ciclópeo de Santa María de Huerta. En la explicación de la destrucción de Arcobriga (Agullera y Gamboa, E. de Arcóbriga?... pág. 10) menciona la existencia de "un nivelador manto de tierra" creado por el desmoronamiento de los tapiales sobre los cimientos de las viviendas, todo ello bajo "una espesa y general capa de cenizas", que puede interpretarse como una indicación estratigráfica, BELTRÁN, M. Arcóbriga... pág. 19. 
Ignoramos qué sistema de registro de datos utilizaba Cerralbo, ya que ... n n $\Omega$ s. conocen diarios ${ }^{23}$, ni se explica el orden descriptivo del yacimiento en las publicaciones. Sus principales aportaciones estriban en el interés por la crítica histórica, en el compromiso de difusión científica de sus trabajos (relacionándose dentro de los ambientes intelectuales del momento) y en la especial importancia concedida al elemento gráfico ${ }^{24}$, como medio para reivindicar los estudios históricos de la Meseta, en aquél momento desconocida.

Mantenía contacto con estudiosos de reconocido prestigio, procedentes de distintas disciplinas, a los que hacía partícipes de sus investigaciones. Así, por ejemplo, Fidel Fita le asesoraba en lo referente a Epigrafía y Numismática, Pedro de Palacios o Eduardo Hernández-Pacheco en cuestiones geomorfológicas y Edouard Harlé en Paleontología ${ }^{25}$; todos ellos visitaron las excavaciones y colecciones, al igual que Emile Cartailhac, Henri Breuil, Pierre Paris, Horace Sandars, Schulten, Polhig y Hugo Obermaier, entre otros. De esta manera en las Universidades, Museos, Academias y centros de trabajo de esos investigadores se conocian las intervenciones de Cerralbo, dotándolas de una mayor difusión internacional.

El Marqués de Cerralbo se interesaba por la fotografía como instrumento óptimo para reproducir los restos materiales, con la mayor fiabilidad posible. Se realizaron fotografías para mostrar parajes en el momento previo, durante y al final de la excavación, efectuando numerosos montajes que permitieran visiones panorámicas del yacimiento y estructuras descubiertas, desde ángulos diferentes y tomas en altura, intentando dotar de relieve a sus ilustraciones. Pretendió ser científica, añadiendo a las composiciones

23 Cabré de Morán, E. y Morán CABRÉ, J.A. "Cabré y la arqueología céltica meseteña del Hierro II". Juan Cabré Aguiló (1882-1982) Encuentro de Homenaje. (Zaragoza, 1982), Zaragoza, 1984, págs. 65-78. En la página 65 indican: “Si bien las excavaciones de Cerralbo fueron realizadas sin diarios, su descubridor procuró que fuesen fotografiados y conservados los ajuares obtenidos, al menos los más importantes,...". Aún en el caso de que no existieran, es seguro que organizó la intormación conseguida durante el trabajo de campo, complementándola y contrastándola con la facilitada por otros estudiosos y la aportada por colaboradores y capataces de la excavación; así lo atestiguan la numeración de los restos desenterrados y las referencias a medidas, encuadres, cómputo de piezas significativas, etc. que se observan en fotos y sobre numerosos objetos arqueológicos (contemplado también en BARRIL, M. y CERDEÑo, M.L. “E Marqués de Cerralbo: un aficionado..." pág. 519-521).

24 «La importancia de la ciudad de Arcóbriga es tanta que para relatar cuánto fué, lo que valió, cómo se halla, y lo que espero sea después de más extensas excavaciones, precisaria un libro y á este trabajo me voy dedicando, pues son indispensables planos que se están haciendo; muchas más fotografías de lugares y objetos que continúanse sacando; análisis crítico, descripciones extensas que procuro escribir y un completo estudio de la época que abarcó..." (AGUILERA y GAMBOA, E. de “Arcóbriga..." pág. 131).

25 NAVASCUÉS, P y JiMÉnEZ, C. «El XVII Marqués de Cerralbo y su aportación...” pág. 510 
escalas gráficas y humanas y recurriendo a las reconstrucciones de usos y situaciones ${ }^{26}$.

Los materiales muebles eran limpiados y ordenados por lotes, fotografiados y numerados los clichés ${ }^{27}$, sin que pueda intuirse que este procedimiento se realizara de manera sistemática, ya que la selección in situ y posterior de los objetos completos o más representativos era frecuente entonces ${ }^{28}$. Los objetos podían fotografiarse por unidades arqueológicas, en series, composiciones escalonadas y espirales, entre otras, prevaleciendo en estas últimas el gusto estético de la composición.

Las fotografías de campo y gabinete eran utilizadas en la ilustración de publicaciones, como complemento gráfico en algunos discursos académicos, en las exposiciones que acompañaban a las comunicaciones de Cerralbo en congresos nacionales e internacionales y en las organizadas en sus palacios de Madrid y Santa María de Huerta.

Para Cerralbo trabajaron fotógrafos profesionales como A. Ciarán y Aurelio Pérez Rioja (después fotógrafo del Museo Numantino y M.A.N.) ${ }^{29}$ y otros menos conocidos o aficionados como Ricardo Oñate ${ }^{30}$, Francisco Alvárez Ossorio (futuro director del M.A.N.) y Cabré, responsable de numerosos reportajes fotográficos y dibujos arqueológicos ${ }^{31}$.

El dibujo se utilizaba en la representación de objetos completos, detalles y decoraciones, reproducción y reconstrucción de formas y delineación de planos generales, parciales, secciones y cortes topográficos, lo que suponía un avance en la representación de estructuras, a pesar de que no

26 Para explicar, por ejemplo, cómo se asía un bifaz paleolítico de Torralba o de qué manera se situaba a la victima en la Pila de los Sacrificios de Monreal de Ariza.

27 CABRÉ, J. «El marqués de Cerralbo (necrología)...” pág. 172.

28 Caballero, L. Arcóbriga $11 .$. pág. 5.

29 VVAA "Censo general de los fotógrafos que han operado en España desde 1839 a 1986" Actas del / Congreso de Historia de la fotografía española 1839-1986, Sevilla, 1986, págs. 538, 591. Ambos figuran en dicho censo, firmando también el fotógrafo soriano como Aurelio Rioja y Aurelio Rioja de Pablo en VVAA Soria entre dos siglos, Catálogo de la exposición, Soria, 1994, págs. 23-25 y VVAA El Museo Numantino, 75 años de la Historia de Soria, Soria, 1994, pág. 126. Consultar también: CONDE, C. "El Archivo Fotográfico Documental del Museo Cerralbo" IV Coloquio Galego de Museos, Investigación e Museos (Pontevedra, 1994), Santiago, 1997, págs. 109-120. VVAA La fotografía y el museo. Madrid, 1997.

30 Se hace referencia a Oñate en: Romero SAntamaría, A. "Historia de la fotografía en Aragón". Actas del / Congreso de Historia de la fotografia española 1839-1986, Sevilla, 1986, págs. 65-83.

31 Aspecto indicado por Cerralbo en las líneas finales de agradecimiento (AGULERA y GAMBOA, E. de “Arcóbriga...." pág. 172); y, posteriormente, por Cabré en la página 339 de su artículo a propósito de la discusión científica que mantuvo con Almagro sobre la veracidad de las fotografias de alineaciones pétreas pertenecientes a las necrópolis meseteñas del Hierro. CABRÉ, J. «El rito céltico de incineración con estelas alineadas" Archivo Español de Arqueología, 49, 1942, págs. 339344. Consultar también: MORÁN, J.A. «El Marqués de Cerralbo y Juan Cabré...", págs. 30-31. 
estuvieran acotados y se hubiesen idealizado en beneficio del trazado rectilíneo de los muros, como advierte Cerralbo ${ }^{32}$. Se añadían escalas y, en algunos casos, indicaba la ubicación de determinados objetos de interés.

El ingeniero Eugenio Muro se encargó de realizar los levantamientos topográficos de Arcobriga y otros enclaves, mientras que Juan Cabré dibujaba, sobre todo, objetos arqueológicos y, en ocasiones, plantas y secciones de tumbas y cuevas. Los elementos cerámicos, metálicos y líticos se dibujaban a tamaño natural y los dibujos a tinta, en ocasiones, se coloreaban a la acuarela ${ }^{33}$.

Muchas líneas más se están escribiendo sobre éste y otros temas referentes al quehacer arqueológico de principios de siglo, al que nos hemos aproximado con el presente trabajo. Para finalizar, recordaremos que el objetivo inicial de las intervenciones de Cerralbo era descubrir si los vestigios del "Cerro Villar" podían corresponder a Arcobriga (nombre que en sus publicaciones siempre acompañó de un signo de interrogación), aspecto que se demostró ya en los años 20 . Crítica aparte merece, entre otras, la hipótesis enunciada tras la primera campaña de excavación que creía identificar allí los indicios de un pobado ibérico que se convertiría en gran ciudad celtíbera y después romana, arrasada por las invasiones alanas en el siglo $\mathrm{V}^{34}$, cuestiones que no pueden mantenerse a la luz de los conocimientos que actualmente poseemos sobre Arcobriga.

32 Agullera y Gamboa, E. de Arcóbriga?... pág. 13.

${ }^{33}$ Es el caso de las armas y adornos pectorales de la necrópolis de Aguilar de Anguita, pintados, según firma, por De la Cadimiere en Nantes y por J. Moya del Pino, respectivamente (Agullera y Gamboa, E. de Páginas de la Historia Patria por mis excavaciones arqueológicas. Tomo III: Aguilar de Anguita, Madrid, 1911 (inédito), lám. XXXVI n. ${ }^{2}$ 2). Recurren también al estudio de paralelos, que dibujan o reproducen, como un vaso fenicio y el altar de Hagiar-Kim (Malta) que relacionan con el "vaso ibero-púnico" de Arcobriga (AGUILERA y GAMBOA, E. de Arcóbriga?..., lám. XXXV) o los calcos de ornamentaciones geométricas paleolíticas y megalíticas que el autor relaciona con los diseños de la "cerámica ibérica" del yacimiento (lám. XLVIII).

${ }^{34}$ Aguilera y Gamboa,E. de "Arcóbriga..." pág. 112. Aguilera y Gamboa, E. de Arcóbriga?... pag. 10. 